\title{
Development of a pre-operative scoring system for predicting risk of post-operative
}

paediatric cerebellar mutism syndrome

Jo-Fen Liu ${ }^{1 *}$, Robert A Dineen ${ }^{1,2,3^{*}}$, Shivaram Avula ${ }^{4}$, Tom Chambers ${ }^{1,3}$, Manali Dutta ${ }^{1}$, Tim Jaspan $^{1,3}$, Donald C MacArthur ${ }^{1,5}$, Simon Howarth ${ }^{1,5}$, Daniele Soria ${ }^{6}$, Philip Quinlan ${ }^{7,8}$,

Srikrishna Harave ${ }^{4}$, Chan Chang Ong ${ }^{4}$, Conor L Mallucci ${ }^{9}$, Ram Kumar ${ }^{10}$, Barry Pizer ${ }^{11}$, and David A Walker ${ }^{2, \S}$

* Joint first authors

$\S$ Senior author

${ }^{1}$ Children's Brain Tumour Research Centre, University of Nottingham, UK;

${ }^{2}$ Radiological Sciences, Division of Clinical Neuroscience, University of Nottingham, UK;

${ }^{3}$ Department of Radiology, Nottingham University Hospitals NHS Trust, UK;

${ }^{4}$ Department of Radiology, Alder Hey Children's NHS Foundation Trust, Liverpool, UK;

${ }^{5}$ Department of Neurosurgery, Nottingham University Hospitals NHS Trust, UK;

${ }^{6}$ Department of Computer Science, University of Westminster, London, UK;

${ }^{7}$ Advanced Data Analysis Centre, University of Nottingham, UK;

${ }^{8}$ School of Computer Sciences, University of Nottingham, UK;

${ }^{9}$ Department of Neurosurgery, Alder Hey Children's NHS Foundation Trust, Liverpool, UK;

${ }^{10}$ Department of Neurology, Alder Hey Children's NHS Foundation Trust, Liverpool, UK;

${ }^{11}$ Department of Oncology, Alder Hey Children's NHS Foundation Trust, Liverpool, UK.

Running title: A risk stratification tool for postoperative CMS 
Corresponding Author:

Dr Rob Dineen

Radiological Sciences, Division of Clinical Neuroscience,

Queen's Medical Centre, University of Nottingham

Nottingham NG7 2UH

United Kingdom

Tel: 01158231173

Fax: 01158231180

Email: rob.dineen@nottingham.ac.uk

Keywords: Cerebellar mutism, posterior fossa syndrome, pre-operative risk assessment, paediatric brain tumours, posterior fossa tumours

Conflict of interest: None to declare.

Funding: None to declare. 


\section{ABSTRACT}

\section{Background}

Despite previous identification of pre-operative clinical and radiological predictors of postoperative paediatric cerebellar mutism syndrome (CMS), a unifying pre-operative risk stratification model for use during surgical consent is currently lacking. The aim of the project is to develop a simple imaging-based pre-operative risk scoring scheme to stratify patients in terms of post-operative CMS risk.

\section{Methods}

Pre-operative radiological features were recorded for a retrospectively assembled cohort of 89 posterior fossa tumour patients from two major UK treatment centers (age 2-23yrs; gender 28M,61F; diagnosis: 38 pilocytic astrocytoma, 32 medulloblastoma, 12 ependymoma, 1 high grade glioma, 1 pilomyxoid astrocytoma, 1 atypical teratoid rhabdoid tumour, 1 hemangioma, 1 neurilemmoma, 2 oligodendroglioma). Twenty-six (29\%) developed post-operative CMS. Based upon results from univariate analysis and C4.5 decision tree, stepwise logistic regression was used to develop the optimal model and generate risk scores.

\section{Results}

Univariate analysis identified five significant risk factors and C4.5 decision tree analysis identified six predictors. Variables included in the final model are MRI primary location, bilateral middle cerebellar peduncle involvement (invasion and/or compression), dentate nucleus invasion and age at imaging $>12.4$ years. This model has an accuracy of $88.8 \%$ (79/89). Using risk score cut-off of 203 and 238, respectively, allowed discrimination into low $(38 / 89$, predicted CMS probability <3\%), intermediate $(17 / 89$, predicted CMS probability 3-52\%) and high-risk (34/89, predicted CMS probability $\geq 52 \%)$. 


\section{Conclusions}

A risk stratification model for post-operative paediatric CMS could flag patients at increased or reduced risk pre-operatively which may influence strategies for surgical treatment of cerebellar tumours. Following future testing and prospective validation, this risk scoring scheme will be proposed for use during the surgical consenting process.

[Word count 270/300] 


\section{INTRODUCTION}

Post-operative paediatric cerebellar mutism syndrome (CMS) (1) is characterized by mutism or reduced speech and emotional lability following cerebellar or 4th ventricle tumour surgery in children. Motor features such as hypotonia, ataxia and neurobehavioral disturbances are commonly associated. There is typically a latent period of 2-5 days between surgery and the onset of the syndrome. Recovery of mutism occurs over weeks to months, but the majority of affected patients have persistently reduced processing speeds with global impact including worse cognitive outcomes than comparable patients without CMS, and are frequently left with persistent motor and non-motor speech disorder $(2,3)$. The estimated incidence of CMS following paediatric posterior fossa surgery is $11-29 \%$ (4).

Providing accurate risk information regarding surgical procedures to the patient and their family is central to the process of seeking informed consent (5). Primary surgery in cerebellar tumours is directed at controlling raised intra-cranial pressure, obtaining a tissue diagnosis and debulking of tumour. However, the overall range of incidences of CMS quoted in the literature do not permit patient specific risks to be estimated, although previous reports have suggested that tumour type (histological and molecular), anatomical location and patient characteristics may have an influence (see Table 1) (6-18). Not all of this information, such as the tumour type or structures damaged during surgery, will be known preoperatively. For example the risk model for the development of CMS proposed by Law et al included determination of tumour pathology in the predictive model (15), although it should be noted that this predictive model was not intended to be used as a pre-surgical risk scoring tool.

These factors are relevant because if a constellation of pre-operative features could be identified to confer either an estimated very low risk or higher CMS risk estimate for 
individuals this would have important clinical implication for approaches to surgery. For the surgeon knowing the risk was low $(<10 \%)$ for the individual case would reinforce their confidence in established surgical approaches. Where the risk was moderate or high new approaches to primary surgery could be explored in risk adjusted clinical trials. For the parent or patient their personal understanding of risk would be enhanced. Where the risk was low, this would enhance confidence and support consent to the current approaches to primary surgery, where the risk was moderate or high, it would support the informed consent process within risk-adjusted trials of new approaches to primary surgery.

(Insert Table 1 here).

Based on the identified lack of a validated pre-operative risk stratification models for use during surgical consent, we performed a retrospective analysis of pre-operative clinical and imaging data to develop an imaging-based risk stratification tool to be applied prospectively. To do this we used data from paediatric posterior fossa tumour cohorts from two major UK treatment centers. The aim of the analysis is to develop a simple risk scoring system that allows stratification of patients into low, intermediate and high risk groups for development of CMS.

\section{MATERIALS AND METHODS}

\section{Study population}

The study population consists of two UK patient cohorts from Nottingham and Liverpool which were assembled retrospectively in a similar way: Nottingham patients were identified from a locally-held database of children who had undergone resection of posterior fossa tumour at Nottingham University Hospital NHS Trust between June 2006 and October 2013. 
The Liverpool cohort included all children who underwent posterior fossa surgery for tumour resection at Alder Hey Children's NHS Foundation Trust between June 2007 and October 2012 and had follow up MRI imaging for at least one year.

Exclusion criteria included patients without complete and available pre-operative scans; patients lacking CMS outcome assessment data; patients who had already undergone partial resection or chemotherapy; patients younger than two years for whom establishing a diagnosis of CMS is difficult due to the limited language development in this group.

\section{Post-operative CMS status and patient factors}

For included cases, post-operative CMS status, defined as markedly reduced or absent speech, was ascertained from clinical notes using a standardized pro-forma. For Nottingham patients, CMS onset and subsequent duration of CMS at any point post-operatively were recorded. Alder Hey recorded decreased speech output at day seven, reasoning that this would minimize confounding post-operative factors causing mutism. Additional patient data including age at surgical resection and sex were recorded. These assessments were conducted separately in within the institutions and were not defined prospectively between institutions. The methods and allocation of mutism status were subsequently compared and validated between investigators (DAW, RK) where it was agreed that the case selection processes were identifying the same features. At this time the consensus definition of CMS had not been agreed or published (1); this experience subsequently informed that consensus process.

\section{Image analysis}


Based on prior literature and the hypothesized mechanism of CMS, imaging features were prospectively defined (Table 2). A single experienced paediatric neuroradiologist (RD) recorded the presence or absence of these imaging features on all cases, blinded to clinical status or clinical outcome, using the data collection form shown in the appendix. In addition, the paediatric neuroradiologist was asked to record tumour size, hydrocephalus based on Evans' index, primary tumour location and their radiological diagnosis of tumour type based solely on pre-operative imaging features.

(Insert Table 2 here)

A second experienced paediatric neuroradiologist (SA) performed an identical evaluation of the imaging data from 20 patients (10 from the Nottingham cohort and 10 from the Liverpool cohort) to allow an assessment of inter-observer agreement of all imaging variables between the radiologists.

\section{Statistical analysis}

In view of the long list of imaging features, a combined approach was used for initial variable selection. Descriptive analysis was used to characterize the study population. T-test, MannWhitney U test, Chi-square or Fisher's exact test were used for comparison between groups as appropriate and odds ratios (ORs) with 95\% confidence intervals were calculated for each variable using logistic regression to identify potential predictors of post-operative CMS.

Potential predictors were also incorporated into the C4.5 Decision Tree Classifier (C4.5) (19) to reproduce the classification into CMS status (Yes/No). C4.5 uses the concept of information gain to generate a visual decision tree or sets of if-then rules that can be easily 
followed and interpreted. It is also a way to reduce the number of variables in the study, as it highlights those variables that play an important role in identifying the outcome. Different scenarios using raw or recoded data were considered to search for the run with the highest overall accuracy and least number of CMS cases misclassified as non-mute (false negative).

Variables reaching significance $(\mathrm{p}<0.05)$ in univariate analysis, together with variables in the decision tree, were used as the inputs in forward and backward stepwise logistic regression models.

The optimal model was developed based upon goodness of fit, classification tables of predicted versus actual group, as well as usefulness in the clinical setting. Multiple logistic regression coefficients for the predictors selected from the optimal model were multiplied by 10 then rounded off to the nearest integer.

In view of the subjective nature of the image assessment, we further tested the inter-observer agreement of four imaging variables selected for inclusion in the final model with a group of experienced paediatric neurosurgeons. These individuals were invited to participate in the image review at an international meeting of neuro-oncology experts, and the review included a subset of 12 cases from the combined cohort (6 with CMS, 6 without CMS). Cohen's kappa or Fleiss's Kappa was used to evaluate inter-observer variation as appropriate. The $K$ value was interpreted as follows: $<0.20=$ Poor, $0.21-0.40=$ Fair, $0.41-0.60=$ Moderate, $0.61-0.80=$ Good, $0.81-1.00=$ Very good $(20)$. 
All analyses other than decision trees were performed with IBM SPSS 22.0 for Windows (IBM Corp. Armonk, NY, USA), and a p < 0.05 was considered statistically significant in all analyses. The C4.5 decision tree analysis was performed using Weka (21).

\section{Approvals}

The data used for the modelling is part of an on-going service evaluation project of existing clinical case data aiming to evaluate and improve outcomes from posterior fossa tumour surgery, and according to UK NHS Health Research Authority guidance (22) does not require Research Ethics Committee (REC) or Institutional Review Board (IRB) approval.

\section{RESULTS}

\section{The combined cohort}

Ninety-nine patients were initially identified based on the inclusion criteria (51 from Nottingham and 48 from Liverpool). Patients who had no pre-operative scan for review ( $\mathrm{n}=8$, no CMS events) and aged under two (n=2, no CMS event) were excluded subsequently. The distribution of age, gender, tumour location, radiological diagnosis, diagnosis, and postoperative CMS rate were examined before data merging (Table S1). There were more ependymoma and less medulloblastoma cases in the Liverpool cohort. No significant difference was observed in other variables between the two patient cohorts.

The combined cohort for analysis therefore consists of 89 patients (28 males and 61 females), age ranged from 2 to 23 years. The most common tumour diagnosis was pilocytic astrocytoma $(n=38 ; 43 \%)$, followed by medulloblastoma $(n=32 ; 36 \%)$, ependymoma $(n=12$; $13 \%)$, atypical teratoid rhabdoid tumour $(n=1 ; 1 \%)$, hemangioma $(n=1 ; 1 \%)$, neurilemmoma $(n=1 ; 1 \%)$ and oligodendroglioma $(n=2 ; 2 \%)$. As for tumour location, about $45 \%$ of the 
patients had tumours in the fourth ventricle $(n=40), 37 \%$ in cerebellar hemisphere $(n=33)$, $13 \%$ in vermis $(n=12)$ and $5 \%$ had tumours at multiple sites $(n=4)$.

(Insert Table S1 here)

\section{Post-operative CMS event rate}

Twenty-six of 89 patients (29\%) developed post-operative CMS; the distribution of their age, gender and MRI imaging features are summarized in Table 3 (data reported as column percentage). Subgroups with high post-operative CMS event rate (Table S2, row percentage $50 \%$ or higher) were found to have bilateral middle cerebellar peduncle (MCP) invasion $(100 \%, 4 / 4)$, bilateral dentate nucleus (DN) invasion $(69 \%, 9 / 13)$, bilateral MCP compression $(67 \%, 10 / 15)$, fourth ventricular location $(53 \%, 21 / 40)$ or multi-sites $(50 \%, 2 / 4)$, and bilateral superior cerebellar peduncle (SCP) invasion $(50 \%, 2 / 4)$. No event was observed in cerebellar hemispheric $(\mathrm{CH})$ tumours $(0 / 33)$.

(Insert Table 3 and Table S2 here)

\section{Initial variable selection}

There were five variables showing significant risk $(\mathrm{p}<0.05)$ in univariate analysis: tumours at fourth ventricle (OR 9.7, 95\% CI 3.2-29.6), invaded to fourth ventricle (OR 9.6, 95\% CI 2.635.2), followed by brainstem invasion, radiological diagnosis of medulloblastoma and superior cerebellar peduncle invasion with odds ratios ranged from 3.2-3.5 (Table 4). On the other hand, tumour at cerebellar hemispheric location showed a strong protective effect; no patient developed CMS in this subgroup. Lowering the significance level to $p=0.1$ did not change the results further, since no other variables showed borderline significance (data not 
shown).

As for supervised machine learning, the model showed the highest accuracy is shown in Figure 1. The six predictors this model selected are: $\mathrm{CH}$ invasion, bilateral MCP invasion, DN invasion, MCP compression, preoperative radiological diagnosis of ependymoma and age at imaging (greater than 12.4 years). This model has an overall accuracy of $91 \%$ and misclassified only 2 out of the 59 patients predicted non-mute.

(Insert Table 4 and Figure 1 here)

\section{Consideration of inter-observer agreement}

Inter-observer agreement between two neuroradiologists for the 20 double-reviewed cases ranged from $0.32-0.69$ on tumour invasion and $0.15-0.77$ on tumour compression (Table S3). The agreement was good ( $\mathrm{k}$ 0.61-0.80) on fourth ventricle compression, fourth ventricle invasion, midbrain invasion; moderate ( $\mathrm{k}$ 0.41-0.6) on vermis invasion, $\mathrm{DN}$ invasion, $\mathrm{SCP}$ invasion, MCP invasion, brainstem invasion, brainstem compression and vermis compression; fair ( $\mathrm{k}$ 0.21-0.4) on SCP compression, midbrain compression and cerebellar hemisphere $(\mathrm{CH})$ invasion; and poor $(\mathrm{k} \leq 0.2)$ on $\mathrm{MCP}$ compression and $\mathrm{CH}$ compression.

(Insert Table S3 here)

Five neurosurgeons were also invited to review a separate subset of 12 patients and scored on the four selected imaging variables and give their feedback. Kappa statistics for interobserver agreement amongst neurosurgeons, ranked from high to low, were: $\mathrm{CH}$ invasion 0.5 , MCP compression 0.45, DN invasion 0.3 and MCP invasion 0.28. Although we cannot 
compare kappa from the two series directly, we note that potential users (neuroradiologists and neurosurgeons) do not have good agreement on MCP compression. Neurosurgeons also commented that it was difficult to decide whether MCP was invaded or just compressed by tumour. We therefore decided to recode MCP invasion and compression into a single variable 'MCP invasion and/or compression' ( $\mathrm{K}=0.50$ amongst neurosurgeons) and included this variable in the subsequent multivariate analysis.

\section{Final model and risk scores}

Age at imaging (greater or less than 12.4 years), MRI tumour location, radiological diagnosis, together with all imaging features identified from the two methods were used as inputs for stepwise logistic regression to structure the optimal model. MCP invasion and MCP compression were replaced with the new variable 'MCP invasion and/or compression'. Cerebellar hemispheric location was also included as a potential protective factor.

All models returned by forward and backward stepwise regression were reviewed. The model showed the highest accuracy and the least number of false negative cases consists of the following predictors: cerebellar hemispheric location $(\mathrm{p}<0.001)$, cerebellar hemisphere invasion $(\mathrm{p}=0.007)$, bilateral MCP invasion and/or compression $(\mathrm{p}=0.006)$, any DN invasion $(\mathrm{p}=0.01)$ and age at imaging $>12.4$ years $(\mathrm{p}=0.027)$.

This optimal model (Table 5) has an accuracy of $88.8 \%$ (79/89), with a sensitivity of $96.2 \%$ (25/26) and specificity of $85.7 \%$ (54/63). Multiple logistic regression coefficients for the predictors were multiplied by 10 then rounded off to the nearest integer (insert Table 5 here). For the ease of clinical interpretation, cerebellar hemispheric location and $\mathrm{CH}$ invasion were combined into three subgroups to describe primary tumour location: cerebellar hemispheric 
location (risk score $=0$ ), midline/non- $\mathrm{CH}$ sites with no $\mathrm{CH}$ invasion (risk score $=218$ ), and midline/non-CH sites with $\mathrm{CH}$ invasion (risk score $=183$ ). Risk scores assigned to other risk factors ranged from 20 (DN invasion, age at imaging greater than 12.4 years) to 23 (bilateral MCP invasion and/or involvement).

Patient's total risk score ranged from 0-281, with a greater number being associated with increased predicted risk of CMS. Using risk score cut-offs 203 and 238 permit discrimination into low $(38 / 89$, predicted probability $<3 \%)$, intermediate $(17 / 89$, predicted probability 3 $52 \%)$ and high-risk (34/89, predicted probability $\geq 52 \%)$, respectively.

(Insert Figure 2 here)

\section{DISCUSSION}

An imaging-based risk stratification model for identifying patients at increased risk of postoperative CMS based on pre-operative features has been developed. Unlike a previously proposed model (15), this scoring system is based purely on information available preoperatively. Following future testing and prospective validation, this risk stratification model is proposed as an adjunct to the surgical consenting process, providing information to patients and their parents / carers in a form that is easy to understand with low $(<10 \%)$, intermediate and high $(>50 \%)$ risk groups. Furthermore, if validated in multiple clinical settings this model may influence surgical decision making and treatment strategies for cerebellar tumours. A larger multicenter retrospective validation of this model using data from European and North American centres is currently underway. 
Pre-operative estimation of a high risk of mutism, particularly at the level that it is more likely to occur than not, if a complete resection is attempted, has implications not just to the extent to which this needs to be discussed in appropriate consenting for surgery but to the surgical strategy itself. Increasingly detailed pre-operative imaging and technical advances with operating microscopes, image guidance systems and ultrasonic surgical aspirators have driven neurosurgeons to attempting complete resection of tumours more often in recent years. Korah and colleagues (13) noted when comparing two eras in their medulloblastoma practice (1990-2000 and 2001-2007) that as the number of patients achieving a complete resection rose from $77 \%$ to $94 \%$, the rate of posterior fossa syndrome more than doubled from $17 \%$ to $39 \%$ and they found absence of radiographic residuum to be a significant predictor of PFS development. Over a similar timescale there have been substantial advances in the understanding of the biology of paediatric brain tumours and medulloblastoma, in particular, such that for many patients cure of the tumour is now a very realistic option, even if there is macroscopic residual tumour left behind at the end of operation.

Neuro-oncology multidisciplinary teams will recognize the potential benefit of having a patient who is clinically in good condition early after surgery and able to progress on to having adjuvant therapy quickly as opposed to one who has undergone a complete resection but is unfit to proceed to prompt follow on radiotherapy due to the profound physical, cognitive and communication difficulties inherent in post-operative paediatric cerebellar mutism syndrome. Furthermore, the potentially permanent consequences for cognitive, physical and communication problems can be a high price to pay for cure. The highest risk patients, with predictive medulloblastoma histology, might well benefit from intentional subtotal resection or a 2-stage surgical strategy using debulking chemotherapy. 
Increasingly, discussions amongst paediatric neurosurgeons suggest that we may be on the brink of an era of less aggressive surgery for selected medulloblastoma patients, just as there has been realization and then widespread acceptance in the last 20 years of the wisdom of a more conservative approach to surgery in craniopharyngioma in children (23). In addition to potentially impacting on the consenting process and surgical strategy, in the future a validated CMS risk score may be also be useful in selecting patients for neuroprotective therapies prior to the emergence of CMS once these have been developed.

The prevailing anatomo-pathological model for the development of CMS is of damage to the proximal dentatothalamic pathway, particularly of the dentate nuclei and $\operatorname{SCP}(4,17,24)$. It is therefore unsurprising that dentate invasion and fourth ventricular location, which would increase the likelihood of dentate or SCP injury, were variables retained in the final model. SCP invasion was identified as a risk factor in the univariate analysis, but was not retained in the final model, whereas involvement of the MCPs was included in the final model. The MCPs are the major afferent pathway to the cerebellum but do not contribute to the dentatothalamic pathway. It is possible that the MCPs have a previously unrecognized direct role in the pathophysiology of CMS, but this association may simply reflect predominance of fourth ventricular tumours in the CMS group.

Dentate nucleus invasion was included in the final model as a binary variable (invasion Yes/No) rather than three categories (none, unilateral, bilateral). We explored a model which DN was entered as three categories, finding that both unilateral and bilateral invasion showed increased risk after adjustment for other risk factors (adjusted OR 9.9, 95\% CI 1.5 - 65.6 and $5.2,95 \%$ CI 0.8 - 33.1 for unilateral and bilateral invasion respectively). Given the small sample size of each stratum, the number of variables fitted in the model and the broad and 
largely overlapping confidence intervals, we decided to go with binary (invasion Yes/No) cut-off in the final model.

An unexpected variable retained in our final model was that age $>12.4$ years was predictive of CMS risk. This is in spite of previous studies observing either no age association or younger age as a risk factor for CMS. Of note, the incidence of CMS was not actually higher in the older age groups (highest in 5-9 year olds). We cannot rule out the possibility that age over 12.4 years is closely associated with another risk factor which was not measured or picked up by our analysis, or it could be by chance. This will require confirmation in further validation studies. Similarly the finding that radiological diagnosis of probable ependymoma conferred lower risk in the decision tree analysis would not have been expected based on existing literature, but this feature was not retained in the final model.

In conducting this study, we have taken a number of steps to minimize bias. The patient data used in this study were unselected consecutive cases from two large and representative paediatric neurosurgery centers in the UK. Definitions of post-operative mutism were consistent across the two cohorts. A number of imaging features were assessed on scans, the choice of which was based on prior literature and current putative anatomical models of CMS. Images from all participants were centrally reviewed using standardized definitions and imaging data capture pro-forma, and inter-observer reliability was assessed for identification of these imaging features. In our statistical analysis we used univariate analysis as well as decision tree analysis to screen for the most important predictors for CMS and to identify the relevant cut points.

We acknowledge a number of important limitations to this work. Firstly, many of the imaging features evaluated on the scans are subjective, which was reflected in the relatively 
poor inter-observer agreement for some of the features. In particular, during the evaluation we often found it difficult to decide whether a structure was invaded by tumour, or just compressed. We found that, for certain anatomical sites, recoding the individual invasion and compression variables into a single variable (i.e. invasion and / or compression) improved inter-observer variation, and in the case of the $\mathrm{MCP}$, the composite variable invasion and / or compression was included in the final model. Nonetheless, we are aware that the subjective nature of the evaluation, despite the clear neuroanatomical definitions, will be a source of concern. For this reason, the tool requires wider testing and prospective evaluation, and may require further refinements and formal training in the application of consistent neuroanatomical definitions.

We also acknowledge that the sample size is relatively small, and that the predictive value of the tool could be skewed by local surgical practice and outcomes at the two centers that contributed data. We also note that our combined cohort had no CMS event in patients with tumours centered in the cerebellar hemisphere whereas other studies have observed CMS in patients with cerebellar hemisphere tumours. Our retrospective dataset did not include handedness data, which is a potential weakness as handedness has previously been related to CMS incidence. We did not have outcome data regarding severity of CMS, and so while our risk score allows prediction of incidence of CMS, it cannot predict severity.

The motivation for the development of this risk model was to identify those at the highest risk of mutism to assist the surgeon in strategy selection to reduce the incidence of this devastating condition. The assumption that more anatomical features were associated with greater risk drove the analysis. The model supports this view to a significant degree. An alternative approach aimed at identifying those at least risk was not considered until after the 
model had been developed. This approach may have significant merit as it would offer the surgeon and parent partnership greater confidence to adopt established techniques for primary surgery in low risk cases and support informed consent processes for novel approaches to surgery in moderate and high risk cases. Overall our intention was highlight the risk of CMS as a complication of posterior fossa tumour surgery in order to reduce its incidence overall, given the devastating consequences for the children and their families post surgery and the long term consequences for survivors and their adult lives.

\section{CONCLUSIONS}

A risk stratification model for post-operative CMS could flag patients at increased risk preoperatively and may influence strategies for surgical treatment of cerebellar tumours. Following future testing and prospective validation in a larger multicenter collaboration, this risk scoring scheme may be further developed and utilized during the surgical consenting process and influence future trial design in astrocytoma and medulloblastoma in particular.

\section{ACKNOWLEDGEMENT}

The authors would like to thank the neurosurgeons who participated in our inter-observer agreement assessment: Marianne Juhler, Department of Neurosurgery, Copenhagen University Hospital Rigshospitalet, Denmark; Robert Keating, Children's National Medical Center, George Washington University School of Medicine, USA; Stephanie Puget, Department of Paediatric Neurosurgery, Necker Enfants Malades Hospital, Paris, France; Jeffrey Wisoff, NYU Langone Medical Center, USA; Kirsten van Baarsen, Radboud University Nijmegen, Nijmegen, The Netherlands. We would also like to thank Dr Tim 
Jaspan, Department of Radiology, Nottingham University Hospitals NHS Trust, for his helpful comments on this manuscript. 


\section{References}

1. Gudrunardottir T, Morgan AT, Lux AL, Walker DA, Walsh KS, Wells EM, et al. Consensus paper on post-operative pediatric cerebellar mutism syndrome: the Iceland Delphi results. Childs Nerv Syst. 2016;32(7):1195-203.

2. Moxon-Emre I, Bouffet E, Taylor MD, Laperriere N, Scantlebury N, Law N, et al. Impact of craniospinal dose, boost volume, and neurologic complications on intellectual outcome in patients with medulloblastoma. Journal of clinical oncology : official journal of the American Society of Clinical Oncology. 2014;32(17):1760-8.

3. Piscione PJ, Bouffet E, Mabbott DJ, Shams I, Kulkarni AV. Physical functioning in pediatric survivors of childhood posterior fossa brain tumors. Neuro-oncology. 2014;16(1):147-55.

4. Gudrunardottir T, Sehested A, Juhler M, Schmiegelow K. Cerebellar mutism: review of the literature. Childs Nerv Syst. 2011;27(3):355-63.

5. Good Surgical Practice. The Royal College of Surgeons of England; 2014.

6. Catsman-Berrevoets CE, Van Dongen HR, Mulder PG, Paz y Geuze D, Paquier PF, Lequin $\mathrm{MH}$. Tumour type and size are high risk factors for the syndrome of "cerebellar" mutism and subsequent dysarthria. J Neurol Neurosurg Psychiatry. 1999;67(6):755-7.

7. Doxey D, Bruce D, Sklar F, Swift D, Shapiro K. Posterior fossa syndrome: identifiable risk factors and irreversible complications. Pediatr Neurosurg. 1999;31(3):131-6.

8. Ersahin Y, Yararbas U, Duman Y, Mutluer S. Single photon emission tomography following posterior fossa surgery in patients with and without mutism. Childs Nerv Syst. 2002;18(6-7):318-25.

9. Robertson PL, Muraszko KM, Holmes EJ, Sposto R, Packer RJ, Gajjar A, et al. Incidence and severity of postoperative cerebellar mutism syndrome in children with medulloblastoma: a prospective study by the Children's Oncology Group. Journal of neurosurgery. 2006;105(6 Suppl):444-51.

10. Kotil K, Eras M, Akcetin M, Bilge T. Cerebellar mutism following posterior fossa tumor resection in children. Turk Neurosurg. 2008;18(1):89-94.

11. McMillan HJ, Keene DL, Matzinger MA, Vassilyadi M, Nzau M, Ventureyra ECG. Brainstem compression: a predictor of postoperative cerebellar mutism. Childs Nerv Syst. 2009;25(6):677-81.

12. Wells EM, Khademian ZP, Walsh KS, Vezina G, Sposto R, Keating RF, et al. Postoperative cerebellar mutism syndrome following treatment of medulloblastoma: neuroradiographic features and origin. J Neurosurg Pediatr. 2010;5(4):329-34.

13. Korah MP, Esiashvili N, Mazewski CM, Hudgins RJ, Tighiouart M, Janss AJ, et al. Incidence, risks, and sequelae of posterior fossa syndrome in pediatric medulloblastoma. Int J Radiat Oncol Biol Phys. 2010;77(1):106-12.

14. Kupeli S, Yalcin B, Bilginer B, Akalan N, Haksal P, Buyukpamukcu M. Posterior fossa syndrome after posterior fossa surgery in children with brain tumors. Pediatr Blood Cancer. 2011;56(2):206-10.

15. Law N, Greenberg M, Bouffet E, Taylor MD, Laughlin S, Strother D, et al. Clinical and neuroanatomical predictors of cerebellar mutism syndrome. Neuro-oncology. 2012;14(10):1294-303.

16. Siffert J, Poussaint TY, Goumnerova LC, Scott RM, LaValley B, Tarbell NJ, et al. Neurological dysfunction associated with postoperative cerebellar mutism. J Neurooncol. 2000;48(1):75-81. 
17. Morris EB, Phillips NS, Laningham FH, Patay Z, Gajjar A, Wallace D, et al. Proximal dentatothalamocortical tract involvement in posterior fossa syndrome. Brain. 2009;132(Pt 11):3087-95.

18. Miller NG, Reddick WE, Kocak M, Glass JO, Lobel U, Morris B, et al. Cerebellocerebral diaschisis is the likely mechanism of postsurgical posterior fossa syndrome in pediatric patients with midline cerebellar tumors. AJNR Am J Neuroradiol. 2010;31(2):288-94.

19. Quinlan JR. C4.5: programs for machine learning: Morgan Kaufmann Publishers Inc.; 1993. $302 \mathrm{p}$.

20. Altman DG. Practical statistics for medical research. London: Chapman and Hall; 1991.

21. Witten IE, Frank E. San Francisco: Morgan Kaufmann. 2000.

22. Defining Research: Health Research Authority; 2013 [Available from: http://www.hra.nhs.uk/documents/2013/09/defining-research.pdf.

23. Sainte-Rose C, Puget S, Wray A, Zerah M, Grill J, Brauner R, et al. Craniopharyngioma: the pendulum of surgical management. Childs Nerv Syst. 2005;21(8-9):691-5.

24. Avula S, Mallucci C, Kumar R, Pizer B. Posterior fossa syndrome following brain tumour resection: review of pathophysiology and a new hypothesis on its pathogenesis. Childs Nerv Syst. 2015;31(10):1859-67. 
Table 1. Summary of published studies that report statistical associations between clinical and structural imaging findings and development of post-operative pediatric cerebellar mutism syndrome.

\begin{tabular}{|c|c|c|c|c|c|c|c|}
\hline \multirow[t]{2}{*}{ Paper } & \multirow{2}{*}{$\begin{array}{l}\text { Target } \\
\text { condition }\end{array}$} & \multirow{2}{*}{$\begin{array}{l}\text { Study Population } \\
\text { Surgical purpose, } \\
\text { age range*, gender }\end{array}$} & \multirow[b]{2}{*}{$\begin{array}{l}\text { CMS rate } \\
\text { (CMS/Total) }\end{array}$} & \multicolumn{2}{|c|}{ Preoperative Factors } & \multicolumn{2}{|c|}{ Postoperative } \\
\hline & & & & Significant risk factors & Other variables considered & Significant risk factors & Other variables considered \\
\hline $\begin{array}{l}\text { Catsman- } \\
\text { Berrevoets } \\
\text { et al, } 1999 \\
(6)\end{array}$ & $\begin{array}{l}\text { Cerebellar } \\
\text { mutism and } \\
\text { subsequent } \\
\text { dysarthria } \\
\text { (MSD) }\end{array}$ & $\begin{array}{l}\text { CTR, 2-17yrs. } \\
29 \mathrm{~m} \mathrm{13f}\end{array}$ & $\begin{array}{l}28.6 \% \\
(12 / 42)\end{array}$ & $\begin{array}{l}\text { Cerebellar midline } \\
\text { location }(\mathrm{OR}=8.2 \text {, } \\
\mathrm{p}=0.004)\end{array}$ & $\begin{array}{l}\text { Patient Age, Gender, Tumor } \\
\text { size, Hydrocephalus }\end{array}$ & $\begin{array}{l}\text { MB pathology }(\mathrm{p}=0.006) \\
\text { Vermian incision (vs lateral) } \\
(\mathrm{p}=0.028) . \\
\text { Tumor size in } \\
\text { medulloblastoma group } \\
(1 \mathrm{~cm} \text { increment } \mathrm{OR}=1.76, \\
\mathrm{p}=0.05)\end{array}$ & $\begin{array}{l}\text { Postoperative infection, } \\
\text { Hydrocephalus }\end{array}$ \\
\hline $\begin{array}{l}\text { Doxey et al, } \\
1999(7)\end{array}$ & PFS & PFTR. & $\begin{array}{l}7.9 \% \\
(20 / 253)\end{array}$ & $\begin{array}{l}\text { Brainstem invasion } \\
(\mathrm{p}<0.05)\end{array}$ & Not stated & Tumor histology $(\mathrm{p}<0.05)$ & Not stated \\
\hline $\begin{array}{l}\text { Ersahin et } \\
\text { al, } 2002(8)\end{array}$ & CMS & $\begin{array}{l}\text { PFTR. 3-11yrs. } \\
6 \mathrm{~m} 5 \mathrm{f} .\end{array}$ & $27.3 \%(3 / 11)$ & Not stated & $\begin{array}{l}\text { Age, Gender, Tumor size, } \\
\text { Tumor location, Hydrocephalus }\end{array}$ & $\begin{array}{l}\text { Brainstem } \\
\text { involvement/clinical signs of } \\
\text { brain stem injury after } \\
\text { surgery }(p=0.003)\end{array}$ & $\begin{array}{l}\text { Tumor histology, Vermian } \\
\text { incision, SPECT } \\
\text { abnormalities }\end{array}$ \\
\hline $\begin{array}{l}\text { Robertson } \\
\text { et al, } 2006 \\
\text { (9) }\end{array}$ & CMS & $\begin{array}{l}\text { PFTR. } \\
277 \mathrm{~m} 273 \mathrm{f}\end{array}$ & $\begin{array}{l}23.8 \% \\
(107 / 450)\end{array}$ & $\begin{array}{l}\text { Brainstem invasion } \\
(\mathrm{p}=0.003) \text { and non- } \\
\text { cerebellar hemisphere } \\
\text { location }(\mathrm{p}=0.002) .\end{array}$ & $\begin{array}{l}\text { Age at diagnosis, Gender, } \\
\text { Tumor location (except } \\
\text { cerebellar hemisphere) }\end{array}$ & CNS infection $(\mathrm{p}=0.024)$ & $\begin{array}{l}>90 \% \text { resection, CSF leak, } \\
\text { Aseptic meningitis }\end{array}$ \\
\hline $\begin{array}{l}\text { Kotil et al, } \\
2008(10)\end{array}$ & CMS & $\begin{array}{l}\text { CTR. 3-13yrs. } \\
\text { 19m 13f. }\end{array}$ & $\begin{array}{l}31.3 \% \\
(10 / 32)\end{array}$ & $\begin{array}{l}\text { Midline tumor location } \\
(\mathrm{OR}=6.7, \mathrm{p}<0.003)\end{array}$ & Not stated & $\begin{array}{l}\text { MB histology } \dagger \text {, Vermian } \\
\text { incision } \dagger \text {. } \\
\text { Tumor size in } \\
\text { medulloblastoma group } \\
(1 \mathrm{~cm} \text { increment } \mathrm{OR}=1.53 \text {, } \\
\mathrm{p}=0.04)\end{array}$ & Not stated \\
\hline $\begin{array}{l}\text { McMillan } \\
\text { et al, } 2009 \\
(11)\end{array}$ & CMS & $\begin{array}{l}\text { PFTR. 1.8-15.8yrs. } \\
\text { 30m 21f. }\end{array}$ & $\begin{array}{l}25.5 \% \\
(13 / 51)\end{array}$ & $\begin{array}{l}\text { Pons anteroposterior } \\
\text { diameter }(\mathrm{p}<0.05)\end{array}$ & $\begin{array}{l}\text { Age at mutism onset, } \\
\text { Maximum Tumor dimensions, } \\
\text { Tumor volume }\end{array}$ & $\begin{array}{l}\text { Change in pons } \\
\text { anteroposterior diameter } \\
\text { following surgery }(\mathrm{p}<0.005)\end{array}$ & $\begin{array}{l}\text { Vermian incision, Surgical } \\
\text { approach taken, Surgical } \\
\text { shunt, Pons anteroposterior } \\
\text { diameter, Tumor angle. }\end{array}$ \\
\hline
\end{tabular}




\begin{tabular}{|c|c|c|c|c|c|c|c|}
\hline \multirow[t]{2}{*}{ Paper } & \multirow{2}{*}{$\begin{array}{l}\text { Target } \\
\text { condition }\end{array}$} & \multirow{2}{*}{$\begin{array}{l}\text { Study Population } \\
\text { Surgical purpose, } \\
\text { age range*, gender }\end{array}$} & \multirow[b]{2}{*}{$\begin{array}{l}\text { CMS rate } \\
\text { (CMS/Total) }\end{array}$} & \multicolumn{2}{|c|}{ Preoperative Factors } & \multicolumn{2}{|c|}{ Postoperative } \\
\hline & & & & Significant risk factors & Other variables considered & Significant risk factors & Other variables considered \\
\hline $\begin{array}{l}\text { Wells et al, } \\
2010(12)\end{array}$ & CMS & $\begin{array}{l}\text { PFTR. } \\
\text { Mean age } 6.19 \\
\text { (CMS) and } 7.05 \\
\text { (non-CMS). } 13 \mathrm{~m} \\
\text { 15f. }\end{array}$ & $\begin{array}{l}39.3 \% \\
(11 / 28)\end{array}$ & $\begin{array}{l}\text { Brainstem invasion } \\
(\mathrm{p}<0.05)\end{array}$ & $\begin{array}{l}\text { Age at diagnosis, Gender, } \\
\text { Tumor size, Tumor location, } \\
\text { Hydrocephalus, Peritumoural } \\
\text { edema, Involvement of } \\
\text { Cerebellar medullary angle or } \\
\text { Cerebellopontine angle }\end{array}$ & Not stated & $\begin{array}{l}\text { Edema of cerebellar } \\
\text { hemispheres, Brainstem, } \\
\text { Dentate nuclei, MCP } \\
(\mathrm{p}=0.051) \text { or SCPs } \\
(\mathrm{p}=0.074) \text {, Vermian incision, } \\
\text { Extraventricular drain use, } \\
\text { Total resection. }\end{array}$ \\
\hline $\begin{array}{l}\text { Korah et al, } \\
2010(13)\end{array}$ & PFS & $\begin{array}{l}\text { MB resection. } \\
>3 \text { yrs (median } \\
8.2 \mathrm{yrs} \text { ). } \\
43 \mathrm{~m} 21 \mathrm{f} .\end{array}$ & $\begin{array}{l}28.6 \% \\
(18 / 63)\end{array}$ & $\begin{array}{l}\text { Univariate: Younger age } \\
(\mathrm{p}=0.018), \text { Midline tumor } \\
\text { location }(\mathrm{p}=0.025), \\
\text { Brainstem invasion } \\
(\mathrm{p}<0.001) \\
\text { Multivariate: Younger age } \\
(\mathrm{p}=0.027)\end{array}$ & Not stated & $\begin{array}{l}\text { Univariate: Absence of } \\
\text { radiographic residual tumor } \\
(\mathrm{p}=0.049) \\
\text { Multivariate: Absence of } \\
\text { radiographic residual tumor } \\
(\mathrm{p}=0.042)\end{array}$ & Vermian incision \\
\hline $\begin{array}{l}\text { Kupeli et al, } \\
2011 \text { (14) }\end{array}$ & PFS & $\begin{array}{l}\text { PFTR. <16yrs. } 21 \mathrm{~m} \\
15 \mathrm{f} .\end{array}$ & $25.0 \%(9 / 36)$ & $\begin{array}{l}\text { Univariate: Midline tumor } \\
\text { location ( } \mathrm{p}=0.05), \text { Low } \\
\text { socioeconomic level } \\
(\mathrm{p}=0.06) \\
\text { Multivariate: Midline } \\
\text { tumor location (OR=6.7, } \\
\text { 95\%CI 1.2-37.5); low } \\
\text { socioeconomic level } \\
(\mathrm{OR}=5.7,95 \% \text { CI } 1.0- \\
32.0)\end{array}$ & $\begin{array}{l}\text { Patient Age, Gender, Tumor } \\
\text { Size, Hydrocephalus, Spinal } \\
\text { seeding }\end{array}$ & $\begin{array}{l}\text { Univariate: } \mathrm{MB} \text { histology } \\
(\mathrm{p}=0.05) \\
\text { Multivariate: } \mathrm{MB}(\mathrm{OR}=7.2 \text {, } \\
\text { 95\% CI 1.0-54.0) }\end{array}$ & $\begin{array}{l}\text { Suboccipital craniotomy, } \\
\text { Gross-total resection, } \\
\text { Existence of shunt, Residual } \\
\text { disease, Edema }\end{array}$ \\
\hline $\begin{array}{l}\text { Law et al, } \\
2012(15)\end{array}$ & CMS & $\begin{array}{l}\text { PFTR. 5-17yrs. } \\
\text { Case-control study: } \\
17 \text { CMS patients } \\
\text { (7m 10f), } 34 \text { non- } \\
\text { CMS patients ( } 21 \mathrm{~m} \\
13 \mathrm{f}) \text { and } 28 \text { healthy } \\
\text { controls }(14 \mathrm{~m} 14 \mathrm{f}) \\
\end{array}$ & $\begin{array}{l}\text { Not } \\
\text { applicable }\end{array}$ & $\begin{array}{l}\text { Univariate: Left- } \\
\text { handedness ( } \mathrm{p}=0.004) \text {, } \\
\text { Larger tumor size } \\
(\mathrm{p}=0.037) \text {. } \\
\text { Multivariate: } \text { Left } \\
\text { handedness } \mathrm{p}=0.02\end{array}$ & $\begin{array}{l}\text { Age at diagnosis, Tumor } \\
\text { location }\end{array}$ & MB histology $(p=0.02)$ & Extent of resection \\
\hline
\end{tabular}




\begin{tabular}{|c|c|c|c|c|c|c|c|}
\hline \multirow[t]{2}{*}{ Paper } & \multirow{2}{*}{$\begin{array}{l}\text { Target } \\
\text { condition }\end{array}$} & \multirow{2}{*}{$\begin{array}{l}\text { Study Population } \\
\text { Surgical purpose, } \\
\text { age range*, gender }\end{array}$} & \multirow[b]{2}{*}{$\begin{array}{l}\text { CMS rate } \\
\text { (CMS/Total) }\end{array}$} & \multicolumn{2}{|c|}{ Preoperative Factors } & \multicolumn{2}{|c|}{ Postoperative } \\
\hline & & & & Significant risk factors & Other variables considered & Significant risk factors & Other variables considered \\
\hline $\begin{array}{l}\text { Siffert et al, } \\
2000(16)\end{array}$ & CMS & $\begin{array}{l}\text { PFTR. 3-12yrs. } 8 \mathrm{~m} \\
\text { 8f. } \\
\text { Matched case- } \\
\text { control study: } 8 \\
\text { CMS cases }(4 \mathrm{~m} \text { 4f) } \\
\text { and } 8 \text { age, sex, } \\
\text { tumour location and } \\
\text { operative procedure } \\
\text { matched non-CMS } \\
\text { controls. }\end{array}$ & $\begin{array}{l}\text { Not } \\
\text { applicable }\end{array}$ & Not stated & Not stated & Not stated & Complete resection \\
\hline $\begin{array}{l}\text { Morris et al, } \\
2009 \text { (17) }\end{array}$ & PFS & $\begin{array}{l}\text { PFTR. <21yrs. } 16 \mathrm{~m} \\
10 \mathrm{f} \\
\text { Case-control study: } \\
10 \text { PFS patients } \\
\text { (10m 0f) and } 13 \\
\text { controls (6m } 7 \mathrm{f}) \\
\text { randomly selected } \\
\text { from } 49 \text { non-CMS } \\
\text { patients }\end{array}$ & $\begin{array}{l}\text { Entire study } \\
\text { cohort } 21 \% \\
(13 / 64)\end{array}$ & $\begin{array}{l}\text { More rostral position in } \\
\text { fourth ventricle }(\mathrm{p}=0.035)\end{array}$ & $\begin{array}{l}\text { Uni- or bi-lateral Cerebellar } \\
\text { hemisphere, Dentate nuclei, } \\
\text { ICP, MCP, SCP, Medulla, } \\
\text { Pons, Thalamic or Cerebral } \\
\text { hemisphere involvement } \\
\text { (judged by T2w), Splay } \\
\text { between SCP, Hydrocephalus. }\end{array}$ & $\begin{array}{l}\text { Uni- or bi-lateral Pons } \\
(\mathrm{p}=0.029), \text { Midbrain } \\
(\mathrm{p}=0.003) \text { and SCP } \\
(\mathrm{p}=0.008) \text { involvement } \\
\text { (judged by T } 2 \mathrm{w} \text { on } \\
\text { immediate postop) }\end{array}$ & $\begin{array}{l}\text { Uni- or bi-lateral Cerebellar } \\
\text { hemisphere, Dentate nuclei, } \\
\text { ICP, MCP, Medulla or } \\
\text { Thalamic involvement } \\
\text { (judged by } \mathrm{T} 2 \mathrm{w} \text { ) }\end{array}$ \\
\hline $\begin{array}{l}\text { Miller et al, } \\
2010(18)\end{array}$ & PFS & $\begin{array}{l}\text { PFTR. 3-11yrs. } \\
\text { Matched case- } \\
\text { control study: } 11 \\
\text { PFS patients and } 11 \\
\text { age, gender matched } \\
\text { non-PFS controls }\end{array}$ & $\begin{array}{l}\text { Not } \\
\text { applicable }\end{array}$ & NS & NS & $\begin{array}{l}\text { Bilateral damage to the } \\
\text { proximal efferent cerebellar } \\
\text { pathway }(\mathrm{OR}=12,95 \% \\
\text { CI1.12-129) }\end{array}$ & \\
\hline
\end{tabular}

$\dagger$ Statistics not provided but stated to be significant in the text.

KEY: CMS: Cerebellar mutism syndrome, PFS: Posterior fossa syndrome, CTR: Cerebellar tumor resection, PFTR: Posterior fossa tumor resection, MB:

Medulloblastoma, SCP: Superior cerebellar peduncle, MCP: Middle cerebellar peduncle, ICP: Inferior cerebellar peduncle. 
Table 2. Definition of imaging features - tumor invasion and compression

\begin{tabular}{|c|c|c|}
\hline Anatomical Site & & Definition \\
\hline \multirow[t]{2}{*}{ Vermis } & Tumor invasion & $\begin{array}{l}\text { Either tumor arises from vermis, or if tumor adjacent to vermis then } \\
\text { there is a lack of distinction between tumor and vermis. }\end{array}$ \\
\hline & Tumor compression & $\begin{array}{l}\text { Compression of vermis with distortion of normal vermian } \\
\text { configuration including effacement of vermian sulci and / or and } \\
\text { marked dorsal or lateral shift. Displacement of vermis alone without } \\
\text { other features does not qualify. }\end{array}$ \\
\hline \multirow[t]{2}{*}{$\begin{array}{l}\text { Cerebellar } \\
\text { hemisphere }(\mathrm{CH})\end{array}$} & Tumor invasion & $\begin{array}{l}\text { Either tumor arises from cerebellar hemisphere }(\mathrm{CH}) \text {, or when the } \\
\text { tumor is primarily located in midline sites ( } 4^{\text {th }} \text { ventricle, cerebellar } \\
\text { vermis) or other non-cerebellar hemispheric sites and extends into / } \\
\text { invades the cerebellar hemisphere beyond the dentate nucleus or } \\
\text { middle cerebellar peduncle }\end{array}$ \\
\hline & Tumor compression & $\begin{array}{l}\text { Compression of } \mathrm{CH} \text { with distortion of normal } \mathrm{CH} \text { configuration } \\
\text { including effacement of ipsilateral cerebellar sulci and ipsilateral } \\
\text { subarachnoid spaces. }\end{array}$ \\
\hline \multirow[t]{2}{*}{ Fourth ventricle } & Tumor invasion & $\begin{array}{l}\text { Either tumor arises within fourth ventricle, or if tumor adjacent to } \\
\text { fourth ventricle then tumor extends to involve the wall of the fourth } \\
\text { ventricle, with or without tumor nodule or seeding of tumor within } \\
\text { the fourth ventricle. }\end{array}$ \\
\hline & Tumor compression & Effacement of fourth ventricle by extrinsic tumor. \\
\hline \multirow[t]{2}{*}{ Brainstem } & Tumor invasion & $\begin{array}{l}\text { Tumor in a location adjacent to the brainstem for which there is no } \\
\text { clear distinction between the tumor and parenchyma of the } \\
\text { brainstem. }\end{array}$ \\
\hline & Tumor compression & $\begin{array}{l}\text { Compression of brainstem with distortion of normal brainstem } \\
\text { configuration, with AP flattening of the brainstem against the clivus, } \\
\text { loss of the ventral pontomedullary indentation and effacement of } \\
\text { the prepontine or medullary cisterns (depending on tumor location). } \\
\text { Displacement of brainstem alone without other features does not } \\
\text { qualify. }\end{array}$ \\
\hline \multirow[t]{2}{*}{ Midbrain } & Tumor invasion & $\begin{array}{l}\text { Tumor involving superior parts of cerebellum or fourth ventricles for } \\
\text { which there is no clear distinction between the tumor and } \\
\text { parenchyma of the midbrain. Example also includes brainstem } \\
\text { invasion. }\end{array}$ \\
\hline & Tumor compression & $\begin{array}{l}\text { Compression of midbrain with distortion of normal midbrain } \\
\text { configuration, with AP flattening and splaying of the ventral } \\
\text { midbrain and superior / dorsal displacement of the tectum. } \\
\text { Displacement of midbrain alone without other features does not } \\
\text { qualify. }\end{array}$ \\
\hline \multirow[t]{2}{*}{$\begin{array}{l}\text { Middle } \\
\text { cerebellar } \\
\text { peduncle (MCP) }\end{array}$} & Tumor invasion & $\begin{array}{l}\text { When tumor clearly invades the MCPs bilaterally or where the } \\
\text { interface between tumor and MCPs is indistinct such that MCP } \\
\text { invasion is thought possible. }\end{array}$ \\
\hline & Tumor compression & $\begin{array}{l}\text { MCP markedly distorted by the tumor mass, with dorso-ventral } \\
\text { thinning of the MCP. Displacement of MCP alone without other } \\
\text { features does not qualify, }\end{array}$ \\
\hline \multirow{2}{*}{$\begin{array}{l}\text { Superior } \\
\text { cerebellar } \\
\text { peduncle (SCP) }\end{array}$} & Tumor invasion & $\begin{array}{l}\text { Either tumor arises from SCP, or if tumor adjacent to SCP then there } \\
\text { is a lack of distinction between tumor and SCP. }\end{array}$ \\
\hline & Tumor compression & $\begin{array}{l}\text { Compression of SCP with distortion of normal SCP configuration } \\
\text { including marked thinning or elongation of the SCP. }\end{array}$ \\
\hline $\begin{array}{l}\text { Dentate Nucleus } \\
\text { (DN) }\end{array}$ & Tumor invasion & $\begin{array}{l}\text { Abnormal signal extends into the region of the dentate nucleus, with } \\
\text { indistinct boundary between the tumor and site of the dentate } \\
\text { nucleus }\end{array}$ \\
\hline
\end{tabular}


Table 3. Distribution of age, gender, radiological diagnosis, MRI tumor location and imaging features by post-operative CMS status.

\begin{tabular}{|c|c|c|c|c|c|c|c|}
\hline & & & \multicolumn{4}{|c|}{ Post-operative CMS } & \multirow[b]{3}{*}{ p-value } \\
\hline & \multicolumn{2}{|c|}{ Total } & \multicolumn{2}{|c|}{ Yes $(n=26)$} & \multicolumn{2}{|c|}{ No $(n=63)$} & \\
\hline & $\mathbf{n}$ & Col\% & $\mathbf{n}$ & Col\% & $\mathbf{n}$ & Col\% & \\
\hline \multicolumn{8}{|l|}{ Age } \\
\hline Mean $\pm S D$ & \multicolumn{2}{|c|}{$9.7 \pm 5.0$} & \multicolumn{2}{|c|}{$9.4 \pm 4.7$} & \multicolumn{2}{|c|}{$9.8 \pm 5.2$} & 0.709 \\
\hline Median (IQR) & \multicolumn{2}{|c|}{$8.9(8.4)$} & \multicolumn{2}{|c|}{$8.0(14.7)$} & \multicolumn{2}{|c|}{$9.4(9.1)$} & 0.691 \\
\hline \multicolumn{7}{|l|}{ Gender } & 0.802 \\
\hline Male & 28 & $31 \%$ & 9 & $35 \%$ & 19 & $30 \%$ & \\
\hline Female & 61 & $69 \%$ & 17 & $65 \%$ & 44 & $70 \%$ & \\
\hline \multicolumn{7}{|c|}{ Pre-operative radiological diagnosis } & 0.004 \\
\hline Ependymoma & 12 & $13 \%$ & 4 & $15 \%$ & 8 & $13 \%$ & \\
\hline Medulloblastoma & 36 & $40 \%$ & 16 & $62 \%$ & 20 & $32 \%$ & \\
\hline Pilocytic astrocytoma & 40 & $45 \%$ & 5 & $19 \%$ & 35 & $56 \%$ & \\
\hline Other & 1 & $1 \%$ & 1 & $4 \%$ & 0 & $0 \%$ & \\
\hline \multicolumn{7}{|l|}{ MRI tumor location } & $<0.001$ \\
\hline Vermis & 12 & $13 \%$ & 3 & $12 \%$ & 9 & $14 \%$ & \\
\hline Cerebellar hemisphere & 33 & $37 \%$ & 0 & $0 \%$ & 33 & $52 \%$ & \\
\hline Fourth ventricle & 40 & $45 \%$ & 21 & $81 \%$ & 19 & $30 \%$ & \\
\hline Other or multi-sites & 4 & $4 \%$ & 2 & $8 \%$ & 2 & $3 \%$ & \\
\hline \multicolumn{8}{|l|}{ MRI image analysis } \\
\hline \multicolumn{8}{|l|}{ MRI Hydrocephalus } \\
\hline Evans' Index > 0.3 & 59 & $66 \%$ & 16 & $62 \%$ & 43 & $68 \%$ & 0.542 \\
\hline \multicolumn{8}{|l|}{ Tumor invasion } \\
\hline Vermis & 47 & $53 \%$ & 17 & $65 \%$ & 30 & $48 \%$ & 0.127 \\
\hline Cerebellar hemisphere & 42 & $47 \%$ & 1 & $4 \%$ & 41 & $65 \%$ & $<0.001$ \\
\hline Brainstem & 39 & $44 \%$ & 17 & $65 \%$ & 22 & $35 \%$ & 0.008 \\
\hline Midbrain & 12 & $13 \%$ & 4 & $15 \%$ & 8 & $13 \%$ & 0.741 \\
\hline Middle cerebellar peduncle & 44 & $49 \%$ & 13 & $50 \%$ & 31 & $49 \%$ & 0.946 \\
\hline Superior cerebellar peduncle & 31 & $35 \%$ & 14 & $54 \%$ & 17 & $27 \%$ & 0.016 \\
\hline Dentate nuclei & 49 & $55 \%$ & 16 & $62 \%$ & 33 & $52 \%$ & 0.430 \\
\hline Fourth ventricle & 51 & $57 \%$ & 23 & $88 \%$ & 28 & $44 \%$ & $<0.001$ \\
\hline \multicolumn{8}{|l|}{ Tumor compression } \\
\hline Vermis & 72 & $81 \%$ & 21 & $81 \%$ & 51 & $81 \%$ & 0.999 \\
\hline Cerebellar hemisphere & 48 & $54 \%$ & 7 & $27 \%$ & 41 & $65 \%$ & 0.001 \\
\hline Brainstem & 45 & $51 \%$ & 14 & $54 \%$ & 31 & $49 \%$ & 0.691 \\
\hline Midbrain & 27 & $30 \%$ & 8 & $31 \%$ & 19 & $30 \%$ & 0.955 \\
\hline Middle cerebellar peduncle & 51 & $57 \%$ & 13 & $50 \%$ & 38 & $60 \%$ & 0.371 \\
\hline Superior cerebellar peduncle & 70 & $79 \%$ & 21 & $81 \%$ & 49 & $78 \%$ & 0.754 \\
\hline Fourth ventricle & 77 & $87 \%$ & 24 & $92 \%$ & 53 & $84 \%$ & 0.497 \\
\hline
\end{tabular}


Table 4 Crude odds ratio (OR) and 95\% confidence interval of the five risk factors reached significant level in univariate analysis, ranked by effect size

\begin{tabular}{|c|c|c|c|c|c|c|}
\hline & \multirow{3}{*}{$\begin{array}{c}\text { Total } \\
(\mathrm{n}=89 \\
\text { ) } \\
\mathrm{n}\end{array}$} & \multicolumn{4}{|c|}{ Post-operative CMS } & \multirow{3}{*}{$\begin{array}{l}\text { Crude OR } \\
(95 \% \mathrm{Cl})\end{array}$} \\
\hline & & \multicolumn{2}{|c|}{ Yes $(n=26)$} & \multicolumn{2}{|c|}{ No $(n=63)$} & \\
\hline & & $\mathrm{n}$ & Col\% & $\mathrm{n}$ & Col\% & \\
\hline MRI tumor location: fourth ventricle & 40 & 21 & $81 \%$ & 19 & $30 \%$ & $9.7(3.2-29.6)$ \\
\hline Tumor invasion: fourth ventricle & 51 & 23 & $89 \%$ & 28 & $44 \%$ & $9.6(2.6-35.2)$ \\
\hline Tumor invasion: brainstem & 39 & 17 & $65 \%$ & 22 & $35 \%$ & $3.5(1.3-9.2)$ \\
\hline Radiological diagnosis: medulloblastoma & 36 & 16 & $62 \%$ & 20 & $32 \%$ & $3.4(1.3-8.9)$ \\
\hline Tumor invasion: SCP* & 31 & 14 & $54 \%$ & 17 & $27 \%$ & $3.2(1.2-8.2)$ \\
\hline
\end{tabular}

*SCP: superior cerebellar peduncle 
Table 5. Variables in the risk prediction model and risk score

\begin{tabular}{lccc}
\hline \multicolumn{1}{c}{ Predictors } & $\begin{array}{c}\text { Regression } \\
\text { coefficient }\end{array}$ & $\begin{array}{c}\text { Adjusted OR } \\
(\mathbf{9 5 \%} \mathbf{~ C l})^{*}\end{array}$ & $\begin{array}{c}\text { Risk } \\
\text { Score }\end{array}$ \\
\hline MRI primary location & & & 0 \\
Cerebellar hemisphere, $\mathrm{CH}$ invasion (+) & - & 1.0 & 218 \\
Midline/other non- $\mathrm{CH}$ sites, $\mathrm{CH}$ invasion (-) & 21.76 & -- & 183 \\
Midline/other non-CH sites, $\mathrm{CH}$ invasion (+) & 18.26 & -- & 23 \\
Bilateral MCP invasion and/or compression & 2.30 & $10.0(1.9-51.6)$ & 20 \\
DN invasion & 1.98 & $7.2(1.6-32.7)$ & 20 \\
\hline Age at imaging > 12.4 yrs & 1.96 & $7.1(1.2-39.9)$ & \\
\hline
\end{tabular}

$\wedge$ no $\mathrm{CMS}$ event. ${ }^{*}$ Adjusted for all variables included in the model 


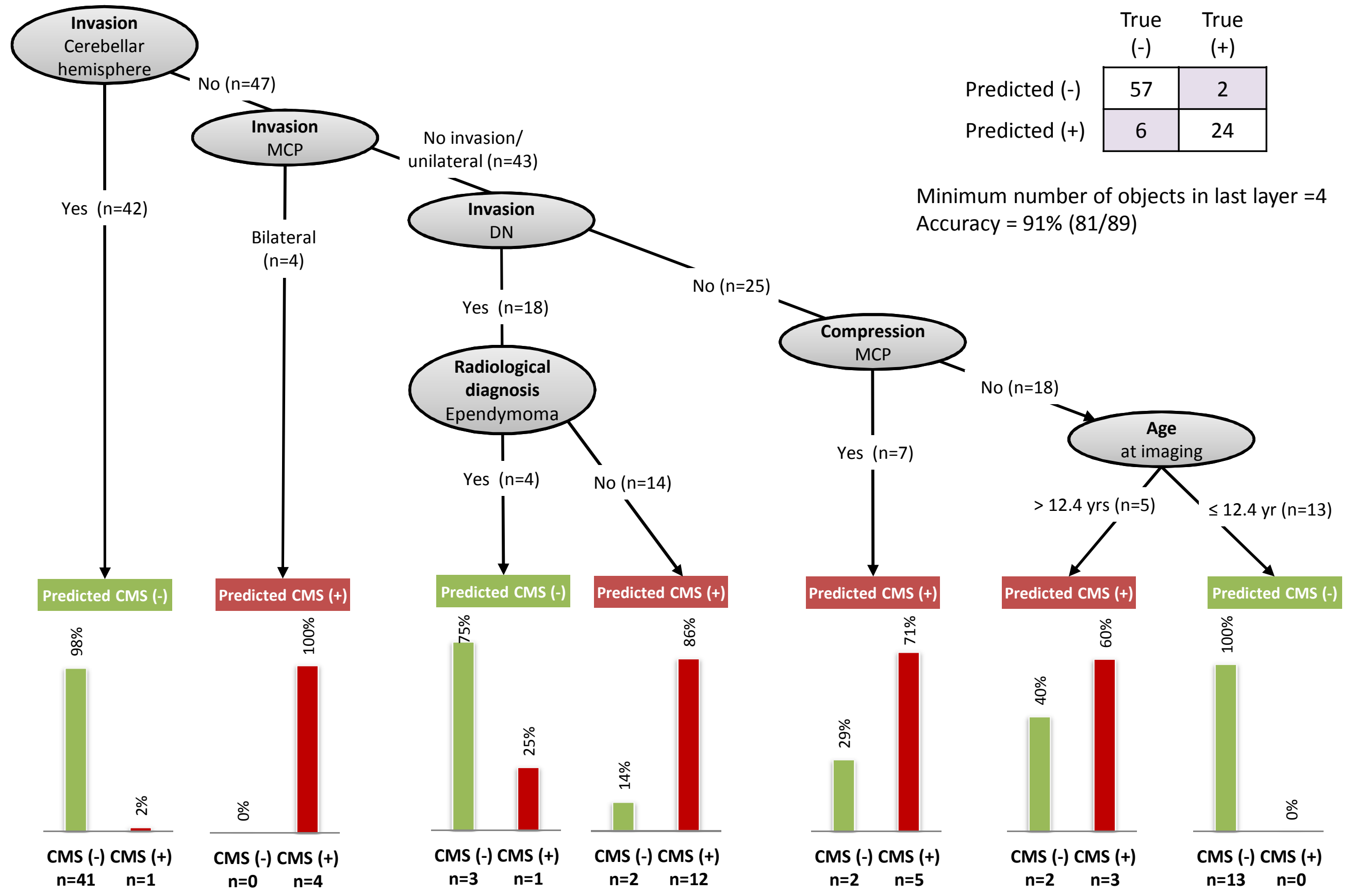

Figure 1. C4.5 decision tree with the highest accuracy $(91.0 \%, 81 / 89)$. Predictors identified were $\mathrm{CH}$ invasion, bilateral MCP invasion, DN invasion, pre-operative radiological diagnosis of ependymoma, MCP compression, and age. 


\section{Low risk Intermediate risk High risk}
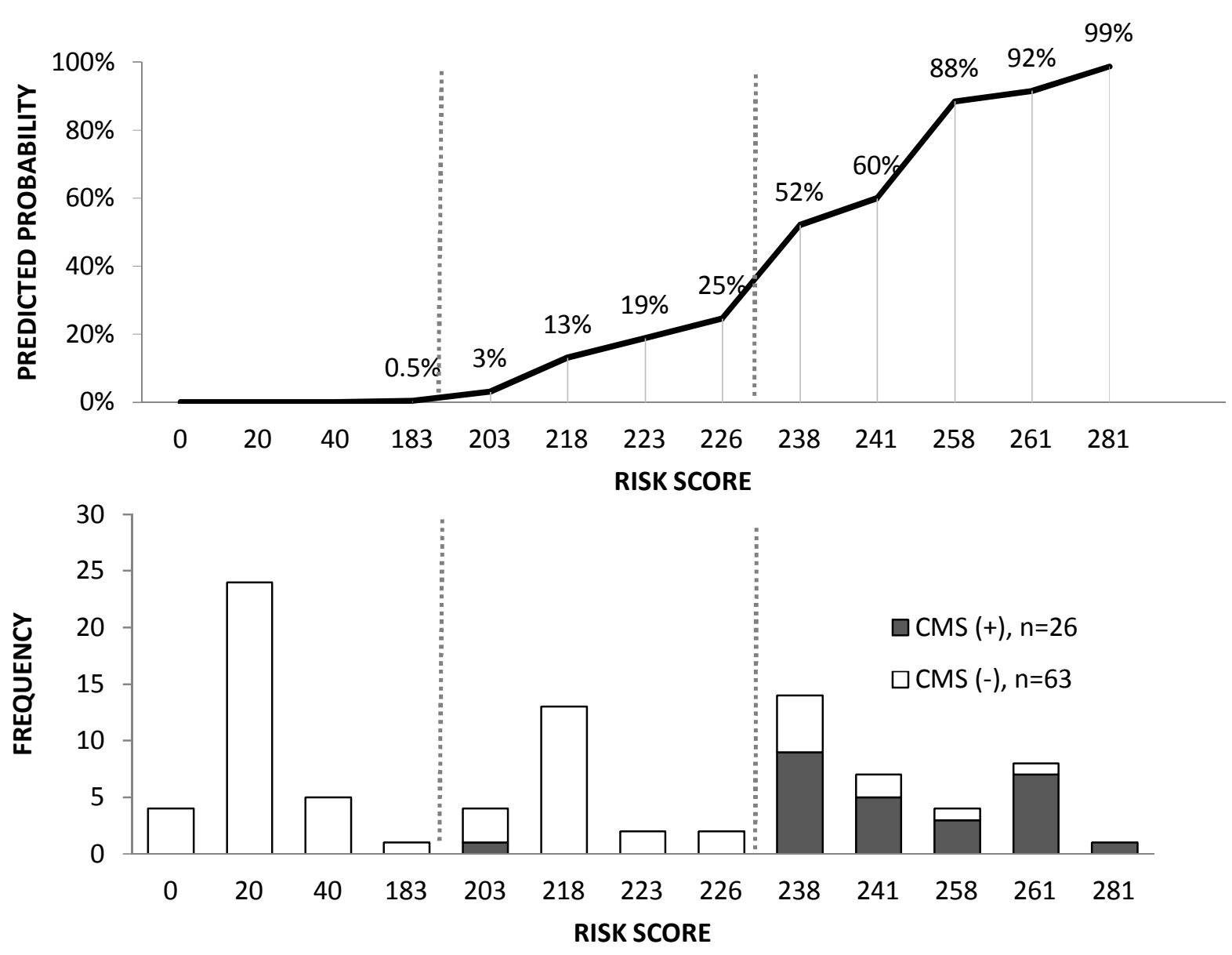

Figure 2. Predicted post-operative CMS probability (top) and distribution of cases (bottom) by risk score 
Table S1. Distribution of age, gender, radiological diagnosis, MRI tumor location and postoperative cerebellar mutism rate of the two cohorts.

\begin{tabular}{|c|c|c|c|c|c|c|c|}
\hline & \multicolumn{2}{|c|}{$\begin{array}{c}\text { Total } \\
(n=89)\end{array}$} & \multicolumn{2}{|c|}{$\begin{array}{c}\text { Alder Hey } \\
(n=38)\end{array}$} & \multicolumn{2}{|c|}{$\begin{array}{c}\text { Nottingham } \\
(n=51)\end{array}$} & \multirow[b]{2}{*}{$p$-value } \\
\hline & $\mathbf{n}$ & Col \% & $\bar{n}$ & Col \% & $n$ & Col \% & \\
\hline Year of surgery & & & 200 & 2012 & 2006 & 2013 & \\
\hline Gender & & & & & & & 0.345 \\
\hline Male & 28 & $31 \%$ & 14 & $37 \%$ & 14 & $27 \%$ & \\
\hline Female & 61 & $69 \%$ & 24 & $63 \%$ & 37 & $73 \%$ & \\
\hline \multicolumn{8}{|l|}{ Age at pre-operative scan } \\
\hline Mean \pm SD (years) & \multicolumn{2}{|c|}{$9.7 \pm 5.0$} & \multicolumn{2}{|c|}{$9.1 \pm 4.6$} & \multicolumn{2}{|c|}{$10.2 \pm 5.3$} & 0.343 \\
\hline min, Max (years) & \multicolumn{2}{|c|}{$2.0,22.9$} & \multicolumn{2}{|c|}{$2.1,17.6$} & \multicolumn{2}{|c|}{$2.0,22.9$} & \\
\hline \multicolumn{7}{|l|}{ Diagnosis } & 0.008 \\
\hline Ependymoma & 12 & $13 \%$ & 9 & $24 \%$ & 3 & $6 \%$ & \\
\hline Medulloblastoma & 32 & $36 \%$ & 8 & $21 \%$ & 24 & $47 \%$ & \\
\hline Pilocytic astrocytoma & 38 & $43 \%$ & 16 & $42 \%$ & 22 & $43 \%$ & \\
\hline Othert & 7 & $8 \%$ & 5 & $13 \%$ & 2 & $4 \%$ & \\
\hline \multicolumn{7}{|l|}{ Radiological diagnosis* } & 0.233 \\
\hline Ependymoma & 12 & $13 \%$ & 8 & $21 \%$ & 4 & $8 \%$ & \\
\hline Medulloblastoma & 36 & $40 \%$ & 15 & $39 \%$ & 21 & $41 \%$ & \\
\hline Pilocytic astrocytoma & 40 & $45 \%$ & 15 & $39 \%$ & 25 & $49 \%$ & \\
\hline Other (non-committal) & 1 & $1 \%$ & 0 & $0 \%$ & 1 & $2 \%$ & \\
\hline \multicolumn{7}{|l|}{ MRI primary tumor location* } & 0.254 \\
\hline Vermis & 12 & $13 \%$ & 7 & $18 \%$ & 5 & $10 \%$ & \\
\hline Cerebellar hemisphere & 33 & $37 \%$ & 11 & $29 \%$ & 22 & $43 \%$ & \\
\hline Fourth ventricle & 40 & $45 \%$ & 17 & $45 \%$ & 23 & $45 \%$ & \\
\hline \multicolumn{7}{|l|}{ Post-operative CMS } & 0.480 \\
\hline Yes & 26 & $29 \%$ & 13 & $34 \%$ & 13 & $25 \%$ & \\
\hline No & 63 & $71 \%$ & 25 & $66 \%$ & 38 & $75 \%$ & \\
\hline
\end{tabular}

${ }^{*}$ Radiologist's estimate. + Hemangioma ( $\left.n=1\right)$, Neurilemmoma $(n=1)$, Atypical Teratoid Rhabdoid Tumour ( $n=1)$, Olidodendroglioma $(n=2)$ 
Table S2 Post-operative CMS event rate in each stratum

\begin{tabular}{|c|c|c|c|}
\hline \multirow[b]{2}{*}{ Predictor } & \multirow[b]{2}{*}{ Total N } & \multicolumn{2}{|c|}{ CMS event } \\
\hline & & $\mathbf{n}$ & $\begin{array}{l}\text { event rate } \\
\text { ( row \%) }\end{array}$ \\
\hline \multicolumn{4}{|l|}{ Centre } \\
\hline Liverpool & 38 & 13 & $34 \%$ \\
\hline Nottingham & 51 & 13 & $26 \%$ \\
\hline \multicolumn{4}{|l|}{ Gender } \\
\hline Female & 28 & 9 & $32 \%$ \\
\hline Male & 61 & 17 & $28 \%$ \\
\hline \multicolumn{4}{|l|}{ Age group } \\
\hline $2-4$ years & 21 & 4 & $19 \%$ \\
\hline $5-9$ years & 29 & 12 & $41 \%$ \\
\hline $10-14$ years & 23 & 5 & $22 \%$ \\
\hline$\geq 15$ years & 16 & 5 & $31 \%$ \\
\hline \multicolumn{4}{|l|}{ Radiological diagnosis } \\
\hline Pilocytic astrocytoma & 40 & 5 & $13 \%$ \\
\hline Ependymoma & 12 & 4 & $33 \%$ \\
\hline Medulloblastoma & 36 & 16 & $44 \%$ \\
\hline Other & 1 & 1 & $100 \%$ \\
\hline \multicolumn{4}{|l|}{ MRI primary location* } \\
\hline Vermis & 12 & 3 & $25 \%$ \\
\hline Cerebellar hemisphere & 33 & 0 & $0 \%$ \\
\hline Fourth ventricle & 40 & 21 & $53 \%$ \\
\hline Other or multi-sites & 4 & 2 & $50 \%$ \\
\hline \multicolumn{4}{|l|}{ MRI Hydrocephalus } \\
\hline Evan's Index > 0.3 & 59 & 16 & $27 \%$ \\
\hline \multicolumn{4}{|l|}{ Tumor invasion } \\
\hline Vermis & 47 & 17 & $36 \%$ \\
\hline Cerebellar hemisphere & 42 & 1 & $2 \%$ \\
\hline Brainstem & 39 & 17 & $44 \%$ \\
\hline Midbrain & 12 & 4 & $33 \%$ \\
\hline Middle cerebellar peduncle & 44 & 13 & $30 \%$ \\
\hline unilateral & 40 & 9 & $23 \%$ \\
\hline bilateral & 4 & 4 & $100 \%$ \\
\hline Superior cerebellar peduncle & 31 & 14 & $45 \%$ \\
\hline unilateral & 27 & 12 & $44 \%$ \\
\hline bilateral & 4 & 2 & $50 \%$ \\
\hline Dentate nuclei & 49 & 16 & $33 \%$ \\
\hline unilateral & 36 & 7 & $19 \%$ \\
\hline bilateral & 13 & 9 & $69 \%$ \\
\hline Fourth ventricle & 51 & 23 & $45 \%$ \\
\hline \multicolumn{4}{|l|}{ Tumor Compression } \\
\hline Vermis & 72 & 21 & $29 \%$ \\
\hline Cerebellar hemisphere & 48 & 7 & $15 \%$ \\
\hline Brainstem & 45 & 14 & $31 \%$ \\
\hline Midbrain & 27 & 8 & $30 \%$ \\
\hline Middle cerebellar peduncle & 51 & 13 & $25 \%$ \\
\hline unilateral & 36 & 3 & $8 \%$ \\
\hline bilateral & 15 & 10 & $67 \%$ \\
\hline Superior cerebellar peduncle & 70 & 21 & $30 \%$ \\
\hline unilateral & 31 & 3 & $10 \%$ \\
\hline bilateral & 39 & 18 & $46 \%$ \\
\hline Fourth ventricle & 77 & 24 & $31 \%$ \\
\hline
\end{tabular}

*Radiologist's estimate 
Table S3. Inter-observer agreement between two neuroradiologists for the 20 doublyreviewed cases

\begin{tabular}{lcc}
\hline & \multicolumn{2}{c}{$\begin{array}{c}\text { Inter-observer agreement (Kappa) } \\
\text { between two radiologists }\end{array}$} \\
\cline { 2 - 3 } Anatomical Site & Invasion & Compression \\
\hline Vermis & 0.60 & 0.44 \\
Cerebellar hemisphere & 0.32 & 0.15 \\
Brainstem & 0.50 & 0.49 \\
Midbrain & 0.64 & 0.34 \\
Middle Cerebellar peduncle & 0.52 & 0.20 \\
Superior Cerebellar peduncle & 0.55 & 0.38 \\
Dentate Nucleus & 0.60 & -- \\
Fourth ventricle & 0.69 & 0.77 \\
\hline
\end{tabular}




\section{CMS assessment}

- Hospital No:

- Date of birth (DD/MM/YYYY):

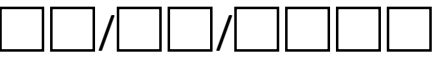

- Age:

- Date of surgery (DD/MM/YYYY):

- Gender: $\square$ Male $\square$ Female

- CMS details:

\section{Nottingham}

- Mutism: $\square$ No $\square$ Yes

- Latency (days):

- Duration (days):

- Date patient first spoke (DD/MM/YYYY):

- Last review (DD/MM/YYYY):

- Additional neuropsychological information:

$\square$ Ataxia

$\square$ Abnormal tongue movements

$\square$ Neurobehavioral changes

\section{Alder Hey}

- Decreased speech output at day 7

- Avolitional at day 7

- Disturbed behaviour at day 7

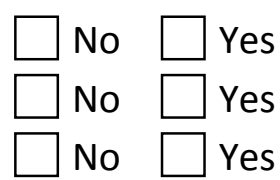

- Additional information

- Presence of other confounders ( $<2$ years, obtunded peri-operatively, decompensated hydrocephalus)

$\square$ No $\square$ Yes

- PFS global severity impression

$\square$ No $\square$ Mild $\square$ Moderate $\square$ Severe 


\section{Imaging data}

1. Hospital number:

2. Date of Birth (DD/MM/YYYY):

3. Gender: $\square$ Male $\square$ Female

4. Date of Pre-op scan (DD/MM/YYYY):

5. MRI Hydrocephalus: Evan's index (e.g., 0.23) binary: $\square$ No $\square$ Yes

6. Pathology estimate

\begin{tabular}{|ll}
$\square$ Ependymoma & $\square$ Pilomyxoid Astrocytoma \\
\hline $\begin{array}{l}\text { High grade glioma } \\
\text { Oedher }\end{array}$ \\
\hline $\begin{array}{l}\text { Medulloblastoma } \\
\square \text { Pilocytic astrocytoma }\end{array}$ & $\square$ Not known
\end{tabular}

7. Tumour size (mm):

$x$ $x$

8. Primary tumour location

\begin{tabular}{|l}
$\square$ \\
$\square$ Vermis \\
$\square$ Right cerebellar hemisphere \\
$\square$ Left cerebellar hemisphere \\
$\square$ Fourth ventricle
\end{tabular}

$\square$ Multi-sites
$\square$ Other

$\square$ Not known

9. Tumour invasion and compression

\begin{tabular}{|l|c|c|}
\hline & Invasion & Compression \\
\hline Vermis & $\square$ No $\square$ Yes & No $\square$ Yes \\
\hline Cerebellar hemisphere, left & $\square$ No $\square$ Yes \\
\hline Cerebellar hemisphere, right & $\square$ No $\square$ Yes & $\square$ No $\square$ Yes \\
\hline Brainstem & $\square$ No $\square$ Yes \\
\hline Midbrain & $\square$ No $\square$ Yes \\
\hline Fourth ventricle & $\square$ No $\square$ Yes \\
\hline Middle cerebellar peduncle, left & $\square$ No $\square$ Yes & $\square$ No $\square$ Yes \\
\hline Middle cerebellar peduncle, right & $\square$ No $\square$ Yes & $\square$ No $\square$ Yes \\
\hline Superior cerebellar peduncle, left & $\square$ No $\square$ Yes & $\square$ No $\square$ Yes \\
\hline Superior cerebellar peduncle, right & $\square$ No $\square$ Yes \\
\hline Dentate nucleus, left & $\square$ No $\square$ Yes \\
\hline Dentate nucleus, right & Nes & \\
\hline
\end{tabular}

